\title{
Expression and prognostic relevance of Cyclophilin $A$ and matrix metalloproteinase 9 in esophageal squamous cell carcinoma
}

\author{
Yi Li ${ }^{* \dagger}$, Hui Guo ${ }^{\dagger}$, Danfeng Dong, Huili Wu and Enxiao Li
}

\begin{abstract}
Aims: To guide clinicians in selecting treatment options for esophageal squamous cell carcinoma (ESCC) patients, reliable markers predictive of clinical outcome are desirable. This study analyzed the correlation of cyclophilin A (CypA) and matrix metalloproteinase 9 (MMP9) in ESCC and their relationships to clinicopathological features and survival.

Methods: We immunohistochemically investigated 70 specimens of ESCC tissues using CypA and MMP9 antibodies. Then, the correlations between CypA and MMP9 expression and clinicopathological features and its prognostic relevance were determined.

Results: Significant correlations were only found in high level of CypA and MMP9 expression with tumor differentiation and lymph node status. Significant positive correlations were found between the expression status of CypA and that of MMP9. Overexpression of CypA and metastasis were significantly associated with shorter progression free survival times in univariate analysis. Multivariate analysis confirmed that CypA expression was an independent prognostic factor.

Conclusions: CypA might be correlated with the differentiation, and its elevated expression may be an adverse prognostic indicator for the patients of ESCC. CyPA/MMP9 signal pathway may be attributed to the malignant transformation of ESCC, and attention should be paid to a possible target for therapy.

Virtual slides: The virtual slide(s) for this article can be found here: http://www.diagnosticpathology.diagnomx.eu/ vs/1166551968105508.
\end{abstract}

Keywords: Esophageal squamous cell carcinoma, Cyclophilin A, Matrix metalloproteinase 9

\section{Introduction}

Esophageal squamous cell carcinoma (ESCC) is a highly aggressive neoplasm with geographic characters and poor prognosis. About one-half of all ESCC cases in the world occur in China [1]. Despite a myriad of improvements in both diagnostic and therapeutic techniques over the past three decades, ESCC continues to have a poor prognosis, with 5-year survival rates between 10-13\% [2]. Research over the last 30 years has identified a number of genetic alterations relating to induction of ESCC. Besides, some of

\footnotetext{
*Correspondence: liyi_0712@163.com

${ }^{\dagger}$ Equal contributors

Department of Oncology, First Affiliated Hospital, Medical School, Xi'an Jiaotong University, Yanta West Road No. 277, Xi'an 710061, Shaanxi
} Province, China them were shown to be of prognostic significance. However, further comprehensive investigations and new clues were expected. To guide clinicians in selecting treatment options for ESCC patients, reliable markers predictive of poor clinical outcome are desirable.

Cyclophilin A (CypA) was originally identified as the intracellular receptor for cyclosporin A (CsA) [3]. It is implicated in several diseases, including viral infection, cardiovascular disease, inflammatory diseases, and cancer [4-7]. The role of CypA in cancer has recently drawn attention. Various cancers, including ESCC over-expressed CypA [8-13]. Although much effort has been devoted to the function of CypA in cancer, but few research has been undertaken to evaluate the clinical value of CypA in ESCC. Matrix metalloproteinases (MMPs) are a highly regulated

\section{Biomed Central}

(c) 2013 Li et al.; licensee BioMed Central Ltd. This is an open access article distributed under the terms of the Creative Commons Attribution License (http://creativecommons.org/licenses/by/2.0), which permits unrestricted use, distribution, and reproduction in any medium, provided the original work is properly cited. 
super family of zincdependent endopeptidases causally associated with the development and progression of tumors [14]. MMP9, a target gene of CypA, was revealed over-expression in ESCC [15].

In this study, we investigated whether expression levels of CypA and MMP9 have prognostic significance in ESCC. Immunohistochemical expression of CypA and MMP9 were examined in a total of 70 ESCC patients who underwent a surgical resection without any neoadjuvant treatment. We also investigated whether the expression levels of CypA correlate with that of MMP9 in this patient population and their prognostic value.

\section{Materials and methods \\ Patients}

ESCC patients who were confirmed by pathology were collected in the First Affiliated Hospital of Xi'an Jiaotong University from 2004 to 2009, and also received surgical treatment. After following-up visits, 70 patients who had complete clinical data were selected. None of these 70 patients received neoadjuvant therapy before operation. Patients were followed closely until December 31, 2012, and the range of the follow-up period was 1 to 25 months (median, 9.33 months). Computed tomography (CT) was performed at least every 6 months to detect recurrence. Differentiation grade, TNM stage and lymph node status were conducted according to UICC/AJCC TNM classification (seventh edition). The clinicopathological features of patients are shown in Table 1. The Institutional Ethics Committee approval for this project was obtained from Institutional Review Board of First Affiliated Hospital of Xi'an Jiaotong University.

\section{Immunohistochemical staining}

Tissue specimens were fixed in neutral buffered formalin $(10 \% \mathrm{v} / \mathrm{v}$ formalin in water; $\mathrm{pH} 7.4)$ and embedded in paraffin wax. Serial sections of $4-\mu \mathrm{m}$ thickness were cut and mounted on charged glass slides. The monoclonal antibody against CypA (1:400; Abcam, Cambridge, UK) and MMP9 (1:800; Santa Cruz Biotechnology, CA, USA) were used respectively. The Streptavidin-Peroxidase technique (Golden Bridge International: SP-9000) was used. An irrelevant rabbit antiserum served as a negative control. Sections were counterstained with Mayer's hematoxylin.

\section{Immunohistochemical analysis}

Two pathologists who were blinded to clinical evaluated staining results independently and co-observed for a consensus when they were divergent with the method as described. Both of the percentage of positive cells and the strength of the staining were considered in the following method. 5 degree magnification visions were chose randomly under the optical microscope, the
Table 1 Clinicopathologic variables and the expression status of CypA

\begin{tabular}{|c|c|c|c|c|c|}
\hline \multirow{2}{*}{\multicolumn{2}{|c|}{ Variables }} & \multirow{2}{*}{$N$} & \multicolumn{2}{|c|}{ СурА } & \multirow{2}{*}{$P$} \\
\hline & & & Low & $\overline{\text { High }}$ & \\
\hline \multirow[t]{3}{*}{ Age } & & & & & 0.242 \\
\hline & $<65$ & 48 & 13 & 35 & \\
\hline & $\geq 65$ & 22 & 3 & 19 & \\
\hline \multirow[t]{3}{*}{ Gender } & & & & & 0.555 \\
\hline & Male & 45 & 9 & 36 & \\
\hline & Female & 25 & 7 & 18 & \\
\hline \multirow[t]{3}{*}{ Smokin } & & & & & 0.343 \\
\hline & Yes (>40 pack-years) & 51 & 10 & 41 & \\
\hline & No & 19 & 6 & 13 & \\
\hline \multirow[t]{3}{*}{ Drink } & & & & & 0.580 \\
\hline & Yes (>50 ml/day) & 39 & 10 & 29 & \\
\hline & No & 31 & 6 & 25 & \\
\hline \multicolumn{2}{|c|}{ Differentiation } & & & & $<0.01$ \\
\hline & Well + Moderate & 39 & 16 & 23 & \\
\hline & Poor & 31 & 0 & 31 & \\
\hline \multicolumn{2}{|c|}{ TNM stage } & & & & 0.123 \\
\hline & $|-| \mid$ & 22 & 8 & 14 & \\
\hline & III-IV & 48 & 8 & 40 & \\
\hline \multicolumn{2}{|c|}{ Lymph node status } & & & & 0.010 \\
\hline & Metastasis & 38 & 4 & 34 & \\
\hline & No metastasis & 32 & 12 & 20 & \\
\hline
\end{tabular}

calculation of results as followed: the percentage of positive cells in $0 \%-5 \%$ was counted 0 ; the percentage of positive cells in 5\%-25\% was counted 1; 26\%-50\% was counted $2 ; 51 \%-75 \%$ was counted $3 ; \geq 76 \%$ was counted 4 . On the respect of staining strength, the score for tumor cells without stain is 0; straw yellow for 1 ; brown for 2; $\tan$ for 3 . The staining index score was the sum of the items above. For the purpose of statistical analysis, the median of this series $(25 \%$ of malignant cells showing a stronger intensity than adjacent non-tumor epithelium) was used as a cutoff value to distinguish tumors with a low $(<25)$ or high $(\geq 25 \%)$ level of CypA and MMP9 expression.

\section{Statistical analysis}

Statistical analysis was done using the SPSS software package (version 13.0, SPSS Institute). The association between staining index and other categorical factors potentially predictive of prognosis was analyzed using the Fisher's exact test. The Spearman's rank correlation coefficient was used for analyzing the association of MMP9 expression levels with CypA expression status. Progression-free survival (PFS) was defined as the time 
from the first day of treatment to the time of disease progression. Survival curve and median survival were estimated by the Kaplan-Meier method. Their differences were verified by log-rank test. Multivariate analysis was done using the Cox proportional hazard regression analysis. Results were considered statistically significant if $\mathrm{P}<0.05$.

\section{Results}

\section{Expression of CypA and MMP9 in ESCC and their} relationships to clinicopathological variables

Levels of CypA and MMP9 were evaluated by immunohistochemical analysis. CypA immunoreactivity showed nuclear and cytoplasmic localization, while MMP9 was found primarily in the cytosol. Figure 1 shows representative expression patterns of CypA and MMP9 in ESCC. Both high level of CypA and MMP9 expression significantly correlated with the tumor differentiation and metastasis. However, the high level rates were not significantly correlated with gender, age, drink, smoking, and TNM stage (Tables 1 and 2).

\section{Association of CypA expression levels with MMP9 expression status}

Since CypA is one of the important transcription factors for MMP9 gene expression, we next investigated the association of CypA expression levels with MMP9 expression status (Table 3). Of the 54 tumors containing a high level of CypA immunoreactivity, a total of 50 cases displayed a high level of MMP9 expression. We calculated the Spearman's rank correlation coefficient to evaluate the linear relationship. There was statistically significant association of CypA expression status with MMP9 expression levels $(r=0.861, \mathrm{P}<0.01)$.

\section{Survival analysis}

Kaplan-Meier analysis was used to calculate the impact of classic clinicopathologic features and protein expression on PFS (Table 4, Figure 2). CypA, MMP9, differentiation, and metastasis were associated with decreased survival $(\mathrm{P}<0.05)$, whereas other clinicopathological variables were not significant. Cox regression analysis revealed a statistically significant correlation between metastasis and CypA expression and PFS ( $\mathrm{P}<0.01$, Table 5).

\section{Discussion}

CypA, an $18-\mathrm{kDa}$ cytosolic protein that is ubiquitously expressed in prokaryotes and eukaryotes, is an important component in protein folding. CypA has an activity of peptidylprolyl cis-trans isomerase, which may play important roles in protein folding, trafficking, assembly, immune-modulator and cell signaling. It displays an

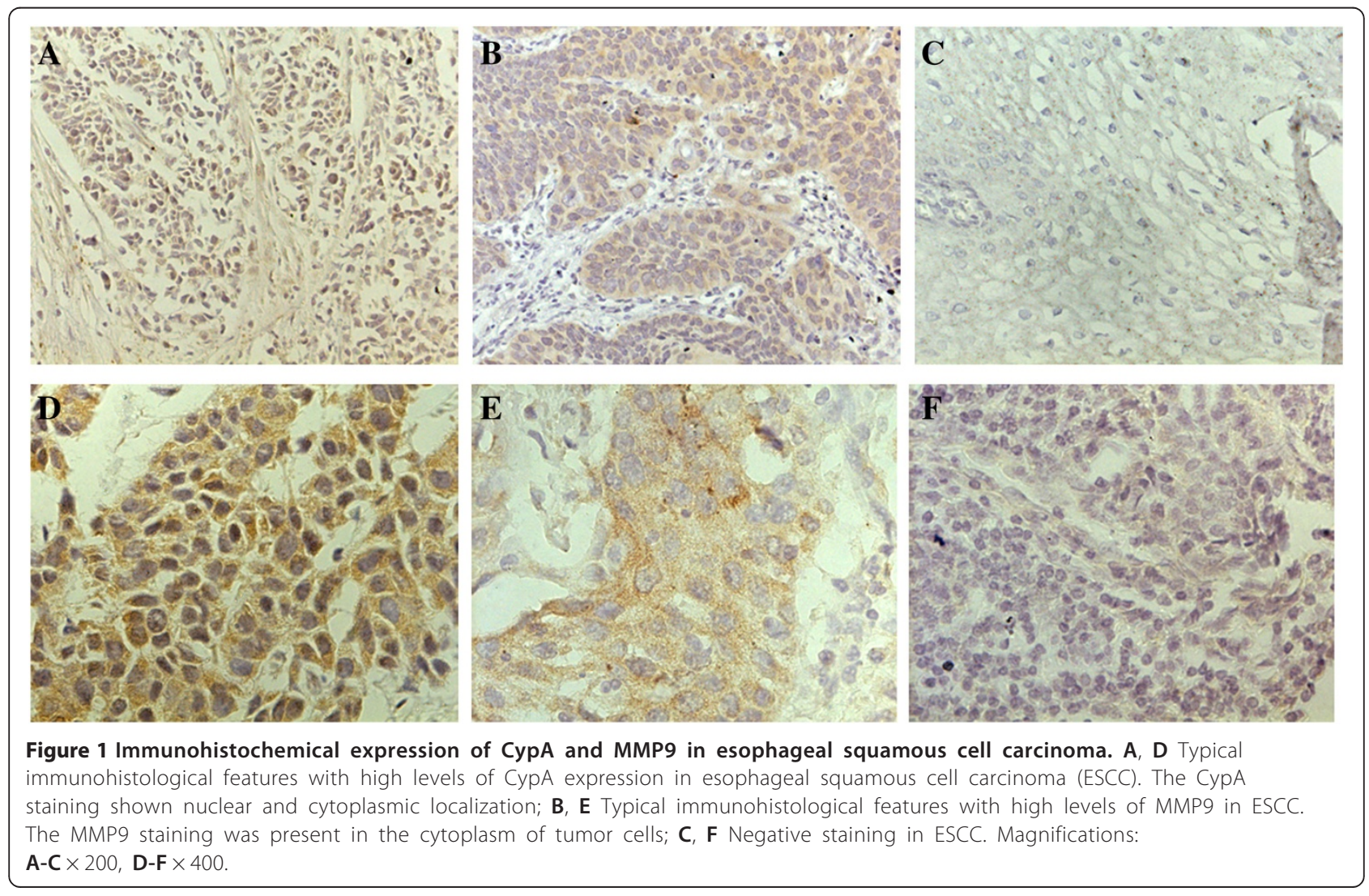


Table 2 Clinicopathologic variables and the expression status of MMP9

\begin{tabular}{|c|c|c|c|c|c|}
\hline \multirow{2}{*}{\multicolumn{2}{|c|}{ Variables }} & \multirow{2}{*}{$N$} & \multicolumn{2}{|c|}{ MMP9 } & \multirow{2}{*}{$P$} \\
\hline & & & Low & High & \\
\hline \multirow[t]{3}{*}{ Age } & & & & & 1.000 \\
\hline & $<65$ & 48 & 14 & 34 & \\
\hline & $\geq 65$ & 22 & 6 & 16 & \\
\hline \multirow[t]{3}{*}{ Gender } & & & & & 0.783 \\
\hline & Male & 45 & 12 & 33 & \\
\hline & Female & 25 & 8 & 17 & \\
\hline \multirow[t]{3}{*}{ Smoking } & & & & 0.146 & 0.301 \\
\hline & Yes (>40 pack-years) & 51 & 12 & 39 & \\
\hline & No & 19 & 8 & 11 & \\
\hline \multirow[t]{3}{*}{ Drink } & & & & & 0.427 \\
\hline & Yes (>50 ml/day) & 39 & 13 & 26 & \\
\hline & No & 31 & 7 & 24 & \\
\hline \multicolumn{2}{|c|}{ Differentiation } & & & & 0.003 \\
\hline & Well + Moderate & 39 & 17 & 22 & \\
\hline & Poor & 31 & 3 & 28 & \\
\hline \multicolumn{2}{|c|}{ TNM stage } & & & & 0.397 \\
\hline & $|-| \mid$ & 22 & 8 & 12 & \\
\hline & III-IV & 48 & 14 & 36 & \\
\hline \multicolumn{2}{|c|}{ Lymph node status } & & & & 0.016 \\
\hline & Metastasis & 38 & 6 & 32 & \\
\hline & No metastasis & 32 & 14 & 18 & \\
\hline
\end{tabular}

unusually high expression in several cancer types and correlates with poor outcome of the patients. Overexpression of CypA was first demonstrated in hepatocellular carcinoma in 1998 [16], then a growing number of reports focus on the role of CypA in cancer. Different types of cancers, including lung cancer, colorectal cancer, pancreatic cancer, breast cancer, squamous cell carcinoma, and melanoma exhibit upregulated CypA [8-13]. Some researchers have investigated the function of CypA during tumor progression, including the stimulation of proliferation, blockade of apoptosis, regulation of metastasis, malignant transformation and drug resistant [17]. In the study of Qi et al. [12], CypA was differentially expressed between esophageal cancer cell lines and immortal cell line, which

Table 3 Association of MMP9 expression levels with CypA expression status

\begin{tabular}{|c|c|c|c|c|c|c|}
\hline \multirow[t]{2}{*}{ Variables } & & \multirow[t]{2}{*}{ Total } & \multicolumn{2}{|c|}{ MMP9 } & \multirow[t]{2}{*}{$P$} & \multirow[t]{2}{*}{$r$} \\
\hline & & & Low & High & & \\
\hline \multirow[t]{3}{*}{ CypA } & & & & & $<0.01$ & 0.861 \\
\hline & Low & 16 & 16 & 0 & & \\
\hline & High & 54 & 4 & 50 & & \\
\hline
\end{tabular}

Table 4 Univariate analysis for progression free survival

\begin{tabular}{|c|c|c|c|c|c|}
\hline \multirow[t]{2}{*}{ Variables } & & \multirow{2}{*}{$\mathbf{N}$} & \multicolumn{2}{|c|}{$\begin{array}{c}\text { Progression } \\
\text { free survival (months) }\end{array}$} & \multirow[t]{2}{*}{$P$} \\
\hline & & & Median \pm SE & $95 \% \mathrm{Cl}$ & \\
\hline \multirow[t]{3}{*}{ CypA } & & & & & $<0.01$ \\
\hline & Low & 16 & $16.42 \pm 1.16$ & $17.08-21.76$ & \\
\hline & High & 54 & $7.42 \pm 0.60$ & $6.24-8.59$ & \\
\hline \multirow[t]{3}{*}{ MMP9 } & & & & & $<0.01$ \\
\hline & Low & 20 & $16.332 \pm 1.75$ & $10.91-14.93$ & \\
\hline & High & 50 & $7.70 \pm 0.62$ & $6.49-8.91$ & \\
\hline \multirow[t]{3}{*}{ Age } & & & & & 0.220 \\
\hline & $<65$ & 48 & $11.47 \pm 1.22$ & $9.08-13.87$ & \\
\hline & $\geq 65$ & 22 & $9.44 \pm 1.23$ & $7.03-11.84$ & \\
\hline \multirow[t]{3}{*}{ Gender } & & & & & 0.950 \\
\hline & Male & 45 & $10.82 \pm 1.24$ & $8.38-13.25$ & \\
\hline & Female & 25 & $11.30 \pm 1.45$ & $8.46-14.15$ & \\
\hline \multirow[t]{3}{*}{ Smoking } & & & & & 0.269 \\
\hline & Yes (>40 pack-years) & 51 & $10.06 \pm 1.02$ & $8.01-12.05$ & \\
\hline & No & 19 & $12.35 \pm 1.82$ & 8.79-15.92 & \\
\hline \multirow[t]{3}{*}{ Drink } & & & & & 0.406 \\
\hline & Yes (>50 ml/day) & 39 & $11.28 \pm 1.25$ & 8.83-13.72 & \\
\hline & No & 31 & $10.07 \pm 11.32$ & $7.48-12.66$ & \\
\hline
\end{tabular}

Differentiation

$$
\begin{array}{llcc}
\text { Well + Moderate } & 39 & 13.33 \pm 1.28 & 10.82-15.84 \\
\text { Poor } & 31 & 7.07 \pm 0.78 & 5.54-8.60
\end{array}
$$

TNM stage

$\begin{array}{llll}\text { I-I } & 22 & 12.02 \pm 1.87 & 8.36-15.67 \\ \text { III-IV } & 48 & 10.20 \pm 1.02 & 8.20-12.19\end{array}$

Lymph node

suggested that CypA may implicated in the esophageal malignant transformation processes. Even so, the expression and significance of CypA in ESCC remains incompletely understood.

Metastasis is the primary cause of morbidity and mortality in cancer patients. Stable CypA RNA-interfered breast cancer and osteosarcoma cells showed reduced migratory capacity [18]. MMPs were also associated with tumor invasion and migration [19]. MMP9 plays a pivotal role in the degradation of ECM [20]. In a microarray results, MMP9 were found regulated by CypA. RNA interference assay also demonstrates that MMP9 were regulated by CypA in SKHep1 cells [21]. The same result was found by Qian et al. in non-small cell lung cancer [22]. Further more, increased expression of MMP9 was found in ESCC [15]. 

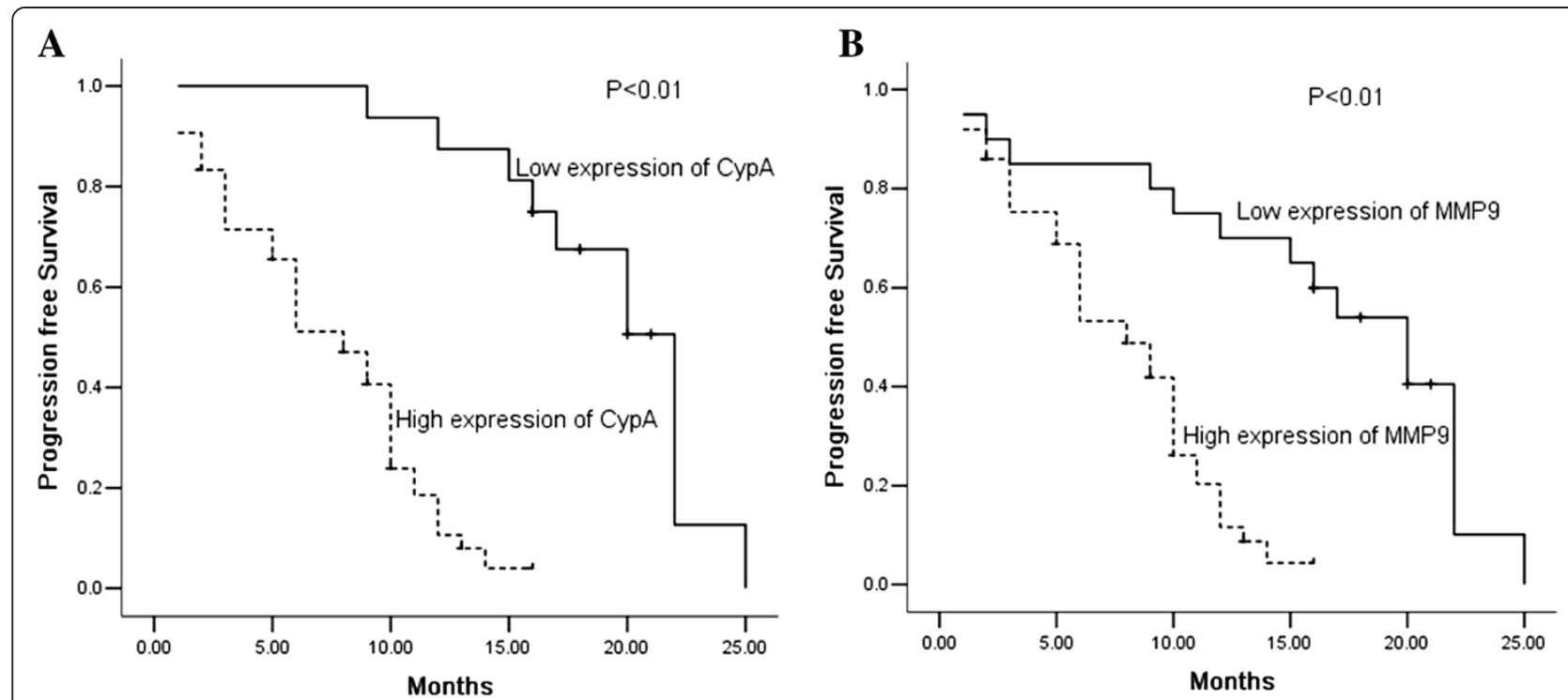

Figure 2 Kaplan-Meier survival analysis. Cumulative progression free survival differences between patients with high and low levels of protein expression. P value was obtained using the log-rank test of the difference. A CypA; B MMP9.

In this study, we showed that CypA and MMP9 were highly expressed in ESCC. Both high level of CypA and MMP9 expression significantly correlated with the tumor differentiation and metastasis. So, we may conclude that both CypA and MMP9 have an important role in the progression of ESCC. Next, significant positive correlations (Spearmen rank correlation) were found between the expression status of CypA and that of MMP9. This means MMP9 may be one of CypA related interacting partners, suggesting that CypA may regulate the expression of MMP9 . However, the exact molecular mechanisms remain to be clarified. Overall, the available data so far suggest that CypA pathway

Table 5 Multivariate Cox proportional hazards analysis for progression free survival

\begin{tabular}{|c|c|c|c|}
\hline \multirow[t]{2}{*}{ Variables } & \multicolumn{2}{|c|}{$\begin{array}{l}\text { Progression } \\
\text { free survival }\end{array}$} & \multirow[t]{2}{*}{$P$} \\
\hline & HR & $95 \% \mathrm{Cl}$ & \\
\hline \multicolumn{4}{|l|}{ CypA } \\
\hline Low vs High & 26.22 & $4.46-154.02$ & $<0.01$ \\
\hline \multicolumn{4}{|l|}{ MMP9 } \\
\hline Low vs High & 2.945 & $0.94-9.24$ & 0.064 \\
\hline \multicolumn{4}{|l|}{ Lymph node } \\
\hline No metastasis vs Metastasis & 0.587 & $0.271-1.274$ & 0.178 \\
\hline \multicolumn{4}{|l|}{ TNM stage } \\
\hline I-II vs III-IV & 0.657 & $0.319-1.353$ & 0.255 \\
\hline \multicolumn{4}{|l|}{ Differentiation } \\
\hline Poor vs Well + Moderate & 1.939 & $0.819-4.59$ & 0.132 \\
\hline
\end{tabular}

may well be related to the genetic changes implicated in ESCC progression.

There are lots of reports about different risk factors in ESCC, including NDRG2, HSPA2, HAX-1, USP9X, and so on [23-27]. The prognostic value of MMP-9 in cancer was also investigated, but there were few reports about that of CypA [28-31]. Although it was found no prognostic significance of CypA in non-small cell lung cancer, but overexpression of CypA was associated with decreased survival in various cancers, including endometrial carcinoma, tongue squamous cell carcinoma, and renal cell carcinoma. However, the prognosis value of CypA in ESCC remains unknown. According to our results, MMP-9 failed to predict patients' prognosis, whereas CypA was shown to be an independent prognostic indicator in patients with ESCC. Take all these results into consideration, CypA might be available not only as clinical predictors, but also as targets for ESCC treatment. We will focus on both the prognostic and treatment value of CypA in furture.

The current study suggested that the high expression of CypA proteins was associated with important clinicopathological parameters in ESCC. There was a significant positive correlation between the expression status of CypA and that of MMP9. Further, CypA was an important prognostic indicator in cases of ESCC. Therefore, CypA/MMP9 signal pathway may be attributed to the malignant transformation of ESCC, and attention should be paid to a possible target for therapy.

Competing interests

The authors declare that they have no competing interests. 


\section{Authors' contributions}

$\mathrm{YL}$ and $\mathrm{HG}$ constructed the manuscript. YL, HG and DD carried out immunohistochemical study. DD, HW and EL were responsible for clinical data; evaluated clinical data; formed analysis of relation between clinical data and survival data. All authors read and approval the final manuscript.

\section{Authors' information}

Yi Li, Hui Guo are co-first authors.

Received: 12 August 2013 Accepted: 6 December 2013 Published: 18 December 2013

\section{References}

1. Parkin DM, Bray FI, Devesa SS: Cancer burden in the year 2000. The global picture. Eur J Cancer 2001, 2001(37 Suppl 8):S4-S66.

2. Umar S, Fleischer DE: Esophageal cancer: epidemiology, pathogenesis and prevention. Nat Clin Pract Gastroenterol Hepatol 2008, 5:517-526.

3. Sherry B, Yarlett N, Strupp A, Cerami A: Identification of cyclophilin as a proinflammatory secretory product of lipopolysaccharide-activated macrophages. Proc Natl Acad Sci U S A 1992, 89:3511-3515.

4. Franke EK, Yuan HE, Luban J: Specific incorporation of cyclophilin A into HIV-1 virions. Nature 1994, 372:359-362.

5. Jin ZG, Melaragno MG, Liao DF, Yan C, Haendeler J, Suh YA, Lambeth JD, Berk BC: Cyclophilin A is a secreted growth factor induced by oxidative stress. Circ Res 2000, 87:789-796.

6. Gwinn WM, Damsker JM, Falahati R, Okwumabua I, Kelly-Welch A, Keegan AD, Vanpouille C, Lee JJ, Dent LA, Leitenberg D, Bukrinsky Ml, Constant SL: Novel approach to inhibit asthma-mediated lung inflammation using anti-CD147 intervention. J Immunol 2006, 177:4870-4879.

7. Lee J, Kim SS: An overview of cyclophilins in human cancers. J Int Med Res 2010, 38:1561-1574.

8. Howard BA, Zheng Z, Campa MJ, Wang MZ, Sharma A, Haura E, Herndon JE 2nd, Fitzgerald MC, Bepler G, Patz EF Jr: Translating biomarkers into clinical practice: prognostic implications of cyclophilin A and macrophage migratory inhibitory factor identified from protein expression profiles in non-small cell lung cancer. Lung Cancer 2004, 46:313-323.

9. Lou J, Fatima N, Xiao Z, Stauffer S, Smythers G, Greenwald P, Ali IU: Proteomic profiling identifies cyclooxygenase-2-independent global proteomic changes by celecoxib in colorectal cancer cells. Cancer Epidemiol Biomarkers Prev 2006, 15:1598-1606.

10. Li M, Zhai Q, Bharadwaj U, Wang H, Li F, Fisher WE, Chen C, Yao Q: Cyclophilin A is overexpressed in human pancreatic cancer cells and stimulates cell proliferation through CD147. Cancer 2006, 106:2284-2294.

11. Hathout Y, Riordan K, Gehrmann M, Fenselau C: Differential protein expression in the cytosol fraction of an MCF-7 breast cancer cell line selected for resistance toward melphalan. J Proteome Res 2002, 1:435-442.

12. Qi YJ, He QY, Ma YF, Du YW, Liu GC, Li YJ, Tsao GS, Ngai SM, Chiu JF: Proteomic identification of malignant transformation-related proteins in esophageal squamous cell carcinoma. J Cell Biochem 2008, 104:1625-1635.

13. Al-Ghoul M, Brück TB, Lauer-Fields JL, Asirvatham VS, Zapata C, Kerr RG, Fields GB: Comparative proteomic analysis of matched primary and metastatic melanoma cell lines. J Proteome Res 2008, 7:4107-4118.

14. Shuman Moss LA, Jensen-Taubman S, Stetler-Stevenson WG: Matrix metalloproteinases: changing roles in tumor progression and metastasis. Am J Pathol 2012, 181:1895-1899.

15. Samantaray S, Sharma R, Chattopadhyaya TK, Gupta SD, Ralhan R: Increased expression of MMP-2 and MMP-9 in esophageal squamous cell carcinoma. J Cancer Res Clin Oncol 2004, 130:37-44.

16. Corton JC, Moreno ES, Merritt A, Bocos C, Cattley RC: Cloning genes responsive to a hepatocarcinogenic peroxisome proliferator chemical reveals novel targets of regulation. Cancer Lett 1998, 134(1):61-71.

17. Obchoei S, Wongkhan S, Wongkham C, Li M, Yao Q, Chen C: Cyclophilin A: potential functions and therapeutic target for human cancer. Med SCi Monit 2009, 15:RA221-RA232

18. Calhoun CC, Lu YC, Song J, Chiu R: Knockdown endogenous CypA with siRNA in U2OS cells results in disruption of F-actin structure and alters tumor phenotype. Mol Cell Biochem 2009, 320:35-43.

19. Kessenbrock K, Plaks V, Werb Z: Matrix metalloproteinases: regulators of the tumor microenvironment. Cell 2010, 141:52-67.
20. Lockwood CJ, Oner C, Uz YH, Kayisli UA, Huang SJ, Buchwalder LF, Murk W Funai EF, Schatz F: Matrix metalloproteinase 9 (MMP9) expression in preeclamptic decidua and MMP9 induction by tumor necrosis factor alpha and interleukin 1 beta in human first trimester decidual cells. Biol Reprod 2008, 78(6):1064-1072.

21. Zhang M, Dai C, Zhu H, Chen S, Wu Y, Li Q, Zeng X, Wang W, Zuo J, Zhou M, Xia Z, Ji G, Saiyin H, Qin L, Yu L: Cyclophilin A promotes human hepatocellular carcinoma cell metastasis via regulation of MMP3 and MMP9. Mol Cell Biochem 2011, 357:387-395.

22. Qian Z, Zhao X, Jiang M, Jia W, Zhang C, Wang Y, Li B, Yue W: Downregulation of cyclophilin A by siRNA diminishes non-small cell lung cancer cell growth and metastasis via the regulation of matrix metallopeptidase 9. BMC Cancer 2012, 12:442.

23. Cao W, Yu G, Lu Q, Zhang J: Low expression of N-myc downstream-regulated gene 2 in oesophageal squamous cell carcinoma correlates with a poor prognosis. BMC Cancer 2013, 13:305.

24. Zhang $\mathrm{H}$, Chen W, Duan CJ, Zhang CF: Overexpression of HSPA2 is correlated with poor prognosis in esophageal squamous cell carcinoma. World J Surg Oncol 2013, 11:141.

25. Li M, Tang Y, Zang W, Xuan X, Wang N, Ma Y, Wang Y, Dong Z, Zhao G: Analysis of HAX-1 gene expression in esophageal squamous cell carcinoma. Diagn Pathol 2013, 8:47

26. Peng J, Hu Q, Liu W, He X, Cui L, Chen X, Yang M, Liu H, Wei W, Liu S, Wang H: USP9X expression correlates with tumor progression and poor prognosis in esophageal squamous cell carcinoma. Diagn Pathol 2013, 8:177

27. Li Z, Zhao X, Bai S, Wang Z, Chen L, Wei Y, Huang C: Proteomics identification of cyclophilin a as a potential prognostic factor and therapeutic target in endometrial carcinoma. Mol Cell Proteomics 2008, 7:1810-1823.

28. Yang J, Li A, Yang Y, Li X: Identification of cyclophilin A as a potential prognostic factor for clear-cell renal cell carcinoma by comparative proteomic analysis. Cancer Biol Ther 2011, 11:535-546.

29. Huang CF, Sun ZJ, Zhao YF, Chen XM, Jia J, Zhang WF: Increased expression of peroxiredoxin 6 and cyclophilin $A$ in squamous cell carcinoma of the tongue. Oral Dis 2011, 17:328-334.

30. Peng Y, Li X, Wu M, Yang J, Liu M, Zhang W, Xiang B, Wang X, Li X, Li G, Shen S: New prognosis biomarkers identified by dynamic proteomic analysis of colorectal cancer. Mol Biosyst 2012, 8:3077-3088.

31. Huang C, Sun Z, Sun Y, Chen X, Zhu X, Fan C, Liu B, Zhao Y, Zhang W: Association of increased ligand cyclophilin A and receptor CD147 with hypoxia, angiogenesis, metastasis and prognosis of tongue squamous cell carcinoma. Histopathology 2012, 60:793-803.

doi:10.1186/1746-1596-8-207

Cite this article as: Li et al.: Expression and prognostic relevance of Cyclophilin A and matrix metalloproteinase 9 in esophageal squamous cell carcinoma. Diagnostic Pathology 2013 8:207.

\section{Submit your next manuscript to BioMed Central and take full advantage of:}

- Convenient online submission

- Thorough peer review

- No space constraints or color figure charges

- Immediate publication on acceptance

- Inclusion in PubMed, CAS, Scopus and Google Scholar

- Research which is freely available for redistribution 